\title{
Discourse, justification and critique: towards a legitimate digital copyright regime?
}

\section{Lee Edwards, Bethany Klein, David Lee, Giles Moss \& Fiona Philip}

To cite this article: Lee Edwards, Bethany Klein, David Lee, Giles Moss \& Fiona Philip (2015) Discourse, justification and critique: towards a legitimate digital copyright regime?, International Journal of Cultural Policy, 21:1, 60-77, DOI: 10.1080/10286632.2013.874421

To link to this article: http://dx.doi.org/10.1080/10286632.2013.874421 \section{(2) 2014 The Author(s). Published by Taylor \&}

曲 Published online: 06 Jan 2014.

Submit your article to this journal

LII Article views: 648

Q View related articles $\longleftarrow$

View Crossmark data $\nearrow$ 


\title{
Discourse, justification and critique: towards a legitimate digital copyright regime?
}

\author{
Lee Edwards, Bethany Klein*, David Lee, Giles Moss and Fiona Philip \\ Institute of Communications Studies, University of Leeds, Leeds, UK
}

(Received 23 August 2013; accepted 3 December 2013)

\begin{abstract}
Digitization and the internet have posed an acute economic challenge to rights holders in the cultural industries. Faced with a threat to their form of capital accumulation from copyright infringement, rights holders have used discourse strategically in order to try and legitimate and strengthen their position in the digital copyright debate with governments and media users. In so doing, they have appealed to general justificatory principles - about what is good, right, and just - that provide some scope for opposition and critique, as other groups contest their interpretation of these principles and the evidence used to support them. In this article, we address the relative lack of academic attention paid to the role of discourse in copyright debates by analysing user-directed marketing campaigns and submissions to UK government policy consultations. We show how legitimacy claims are justified and critiqued, and conclude that amid these debates rests some hope of achieving a more legitimate policy resolution to the copyright wars - or at least the possibility of beginning a more constructive dialogue.
\end{abstract}

Keywords: copyright policy; discourse; legitimacy; sociology of justification; Norman Fairclough; Luc Boltanski

The 'copyright wars' (Lessig 2008) rage on. Rights holders in the cultural industries have continued their battle against online 'piracy' in various ways through legal actions, marketing campaigns and by lobbying governments for favourable regulation. Governments in a number of countries have responded with legislation designed to tackle illegal downloading and file sharing, such as the HADOPI law in France (2009) and the Digital Economy Act in the UK (2010). Meanwhile, as evident in the protests against the Stop Online Piracy and Protect Intellectual Property Acts in the United States in 2011-2012, efforts to regulate copyright online are contested by users and campaign groups as well as by commercial competitors who favour different regulatory settlements.

Discourse has played an important and yet arguably under-researched role in the copyright wars. As Fairclough (2004, p. 2, see also Jessop 2002) argues, discourse becomes particularly important strategically during periods of economic uncertainty and change, where a previously stable set of economic practices are challenged and so economic actors must compete to establish or re-establish a hegemonic 'fix' in the 'co-regulation of regimes of accumulation and political

*Corresponding author. Email: b.klein@leeds.ac.uk 
regimes'. Digital media has posed an acute economic challenge to rights holders in the cultural industries: digital reproduction has allowed users to create flawless copies of cultural products while the internet has facilitated their widespread distribution. Faced with a threat to their means of capital accumulation, rights holders have turned to discourse in order to try and encourage users to self-regulate their behaviour and consume content legally and to persuade governments to introduce regulation that is favourable to their interests.

This article analyses how rights holders in the film, music and television industries have used discourse in order to legitimate and further their position in the digital copyright debate, focusing on recent industry marketing campaigns aimed at users and industry submissions to two major reviews of copyright commissioned by the UK government: The Gowers Review of Intellectual Property in 2006 and the Hargreaves Review of Digital Opportunity and Growth in 2011. In so doing, we emphasize how discourse can play a strategic role, alongside structural advantages, in promoting the interests of particular groups (Jessop 2002, Fairclough 2004). At the same time, our analysis suggests that discourse should not be reduced entirely to economic interests and so dismissed as just so much more ideology in the Marxian sense. Rather, as emphasized in Boltanski and Chiapello's (2005 [1999]) sociology of capitalism and Boltanski and Thévenot's (2006 [1991]) sociology of justification and critical capacity (see also Chiapello and Fairclough 2002), we argue that in legitimating economic arrangements actors appeal to general justificatory principles - about what is good, right and just - which involve a broader claim to public legitimacy. Such justificatory claims provide some scope for opposition and critique, as other groups contest the interpretation of these principles and the evidence used to support them. We conclude that amid these debates rests some hope of achieving a more legitimate resolution to the copyright wars or at least of beginning a more constructive dialogue. However, this will only become a reality through a more deliberative process of policy-making, where the discursive claims of actors are exchanged and debated more fully (Habermas 1997, Young 2002).

\section{Copyright discourse and justification}

There are various philosophical justifications of copyright. A broad distinction is between perspectives that stress the intrinsic value of copyright as an end in itself and those that focus on its instrumental value as a means to some other end (Drahos 1996). For example, copyright may be justified intrinsically as a natural right that cultural producers possess, either because (following Locke) their cultural works are born from their labour or because (following a German idealist tradition) they express their personality (Kretschmer and Kawohl 2004). Yet copyright may also be justified more instrumentally in terms of its beneficial effects. For example, copyright may be viewed as providing an incentive to produce cultural products, which then increases the supply of cultural goods overall. In this view, copyright is a response to what economists call the 'public good' nature of cultural products: given that the consumption of the product does not diminish its value or exclude others from consuming it, producers are unable to benefit from it financially unless they limit access (Baker 2002, p. 15, Hesmondhalgh 2007, p. 150). Rather than view copyright as an unlimited right, an instrumental perspective suggests that copyright is justified only in so far as it is supports another end: the overall supply of cultural goods. Limits should be placed on copyright where it does not serve this 
purpose. Since copyright emerged in the Statute of Anne in 1710, UK copyright law has rejected the notion of copyright as an unlimited right, and instead restricted it to a particular period of time, after which goods fall back into the "public domain' and are available for future creators and the public to use freely (Kretschmer and Kawohl 2004). ${ }^{1}$

The translation of copyright principles into policy is necessarily a political process. Policy-makers become the target of actors who wish to influence the direction of copyright policy and regulation. However, not all the relevant 'stakeholders' have an equal say in the debate. Considerable research has revealed how in practice copyright is designed, enacted in law and managed in the context of inequitable economic and political structures (Bettig 1996, Macmillan 1998, Towse 1999, Drahos and Braithwaite 2002, Lessig 2004, May 2004, Freedman 2008, David 2010). Digital technologies pose a threat to those who benefit from the existing copyright regime and corporate rights holders, fearing a loss of ownership and profit, have worked vigorously to protect their rights. Meanwhile, users risk illegal behaviour in their daily routines and the potential benefits associated with the free circulation of goods through the public domain or the commons are sidelined (May 2003, Lessig 2004, Duff 2008, Boyle 2010). As has been argued elsewhere, the emphasis on private ownership of intellectual property may exacerbate existing economic and cultural inequalities (Macmillan 1998, May 2003, Bowrey 2005, Smiers 2005, Hesmondhalgh 2006) and limits users to the role of consumers rather than creators (Wang and Zhu 2003, Lessig 2008, Pang 2008, Rutter and Bryce 2008, David 2010, Kawashima 2010, Postigo 2011, Svensson and Larsson 2012).

The defence of the existing copyright regime is achieved in part through discourse and discursive processes of legitimation (Chiapello and Fairclough 2002, Boltanski and Chiapello 2005). For example, while the private ownership of cultural goods allows rights holders to profit financially, it is also defended as being in the public interest since it fosters creativity and increases the supply of cultural products in society. Past research on copyright discourse has described the role that various 'myths' around individual creativity, authorship and property play in legitimating copyright and the copyright system (Deazley 2006, Pang 2008, Yar 2008). As Fairclough $(2003,2004)$ argues, while such discourses are a necessary and enduring aspect of all social practices, discursive work becomes particularly important to actors strategically during periods of change, where a previously stable set of practices (and so associated discourses) is challenged (Jessop 2002, Fairclough 2004). For example, faced with a threat to existing economic arrangements from copyright infringement, rights holders have sought to use discourse strategically in order to shore up their position and reinforce the existing 'political-economic regulative fix' (Fairclough 2004, p. 2) around copyright.

While discourses may be used strategically by economic groups, they are not entirely reducible to economic interests. At least, in seeking to justify their positions, actors must draw on more general justificatory principles - about what is good, right and just - which make a broader claim to legitimacy (Chiapello and Fairclough 2002, Boltanski and Chiapello 2005, Boltanski and Thévenot 2006). We need here to steer a course between an economically reductionist account of discourse, which sees it merely as a smokescreen for economic interests, and an equally crude idealism, which ignores the reality of economic imperatives. As Boltanski and Chiapello (2005, p. 26) argue in their discussion of the role of ideology in capitalism: 
In taking the effects of the justification of capitalism in relation to a common good seriously, we distance ourselves both from critical approaches for which only capitalism's tendency to unlimited accumulation at any price is real, and the sole function of ideologies is to conceal the reality of all-powerful economic forces; and from apologetic approaches which, confusing normative support and reality, ignore the imperatives of profit and accumulation, and place the demands for justice by capitalism at its heart.

Boltanski and Chiapello (2005, pp. 26-27) suggest that the tension between these positions can be connected with the ambiguous meaning of the term 'legitimate' and its derivatives 'legitimation' and 'legitimacy'. On the one hand, discourse is involved in legitimation where actors draw upon discourses strategically in order to justify their particular interests and further their own position. On the other hand, when actors justify their positions they often need to appeal to principles about what is in the general interest that involve broader claims to legitimacy. The public appeal to legitimacy creates a resource for critique for other groups, who contest the interpretation of principles and the evidence used to support them. In Habermas's (1989) terms, we can describe legitimation attempts as a form of 'strategic action', as in discourse oriented towards the pursuit of particular interests and objectives. Legitimacy, on the other hand, would depend on the agreement of all affected groups and requires something that more closely approximates 'deliberation', as in communication oriented towards reaching shared justifications and more generalizable interests (Habermas 1991, pp. 178-207, 1997).

We aim in the analysis that follows to extend existing research by examining how rights holders have employed discourse strategically in an attempt to legitimate the current copyright regime and how, at the same time, other groups challenge the claims they make. Analysing copyright discourses is made difficult by their diffuse nature and broad circulation. However, data can be gathered from the PR, marketing and educational campaigns of rights holders and some of the alternative messages circulated in the public sphere by campaign groups. In their communication to users, rights holders aim to reinforce the importance of legal consumption of copyrighted material, while opposing voices present alternative discourses. Postigo (2008), for example, has examined how members of the campaign group Electronic Frontier Foundation discursively frame the concept of 'fair use' in ways that construct users as legitimate partners in cultural production and attempt to counter simplistic industry notions of 'piracy' and 'theft'. Similarly, Lindgren (2013) examines debates over the morality of piracy and the discourses circulated by pro-piracy groups in the Swedish public sphere. In our case, the marketing campaigns of rights holders and the attempts of opposing groups to counter these claims provide a valuable source of user-directed discourses.

In the policy context, meanwhile, rich data for discourse analysis can be obtained from exchanges of opinion and evidence about copyright between governments, organizations and individuals within consultation exercises. In the UK, for example, six government consultations and reviews related to copyright have been published since 2006 under two successive governments (Gowers 2006, Department of Culture, Media and Sport (DCMS) 2007, Department for Business, Enterprise and Regulatory Reform (BERR) 2008, Department for Business, Innovation and Skills (BIS)/DCMS 2009 and Department for Business, Innovation and Skills/Intellectual Property Office (BIS/IPO) 2009, Hargreaves 2011). These reviews elicited numerous responses from various organizations and provide plentiful material for discursive analysis. 


\section{Discourse analysis and method}

According to Fairclough (2003), discourse is a fundamental element of all social practices, which is connected with other, non-discursive parts of social life (such as technologies, resources, social actors and so on). As such, discourse contributes to the reproduction of social practices and the constitution of social order. As already suggested, though, discursive work arguably becomes especially important in strategic terms during periods of uncertainty and change (Jessop 2002, Fairclough 2004). Our analysis focuses on how rights holders in the cultural industries, faced with the problem of copyright infringement, have drawn upon specific discourses (that is, particular ways of representing aspects of the world) in order to try and legitimate the current copyright regime, and on how their claims have been challenged by other groups.

To examine discourses directed towards users, we analysed 24 corporate and industry association websites, which included material from marketing campaigns relating to copyright, as well as informational web pages explaining copyright and its importance. From these, we selected four campaigns for more detailed analysis (Industry Trust for IP Awareness (hereafter Industry Trust) 2009, 2011, Bendelack/ Industry Trust 2010, Music Matters 2012), since they appeared to be indicative of the most prevalent discourses. To explore the circulation of alternative messages in the public sphere that contest these discourses, we also examined the websites of six campaign and consumer groups on copyright, and we focus our discussion below on three in particular: Creative Commons (2011); Featured Artists Coalition (and Music Managers Forum) (hereafter, FAC/MMF) (FAC/MMF 2011) and the Open Rights Group (hereafter, ORG) (ORG 2012a). Creative Commons supports creators in sharing their work via additional free licences, FAC/MMF campaigns for the rights of featured artists and ORG campaigns for digital rights on behalf of users.

To examine discourses directed towards governments, we focus on the two most significant recent reviews of copyright in the UK: The Gowers Review of Intellectual Property (hereafter, Gowers 2006) and Digital Opportunity: A Review of Intellectual Property and Growth (hereafter, Hargreaves) (Hargreaves 2011). These wide-ranging reviews were commissioned by incumbent governments in order to consider intellectual property and copyright in the context of globalization and digitization. Gowers was initiated under the Labour government, while Hargreaves is more recent and was conducted under the Conservative-Liberal Democrat coalition government. Both reviews generated a significant number of responses from industry, trade associations, consumer and campaign groups, and individuals: the Gowers panel received over 500 submissions and the Hargreaves panel nearly 300. Of these, we selected seven submissions from industry bodies (as representative of the key corporate rights holders) for more detailed analysis. These were the British Recorded Music Industry (hereafter, BPI) (BPI 2006, 2011); the British Video Association (hereafter, BVA) (BVA 2006, 2011); the Producers Alliance for Cinema and Television (hereafter, PACT) (PACT 2011); UK Music (2011); and Warner Bros. (2006). To explore how these discourses are contested, we analysed five submissions from alternative and oppositional groups: the Open Rights Group (hereafter, ORG) (ORG 2006, 2011); Creative Commons (2006); the (FAC/MMF 2011), and the Association of Independent Music (hereafter, AIM) (AIM 2011), which is the trade body for independent music companies in the UK. 
As Fairclough (2003, pp. 65-86) argues, the 'genres' or 'generic structures' (that is, the particular forms of social action and interaction) through which discourses are circulated can play an important role in shaping how discourses are used. Marketing campaigns aimed at consumers are persuasive, pedagogical exercises, which aim to construct an emotional connection between author and audience. The reader is often addressed directly through the use of narrative. In government consultations, by contrast, submissions respond to formal requests for evidence and are underpinned by a genre that emphasizes evidence and expert knowledge: they tend to be written in an impersonal style and use statistical data to back up claims.

We considered the importance of genre as well as discourse in our analysis, especially in relation to whether the generic structures of marketing campaigns and government consultations allow for a meaningful, deliberative exchange of views about copyright. However, our analysis focuses mainly on the specific discourses and justifications evident in the texts. These discourses were reflected in themes that emerged inductively through a three-step coding process. First, a close reading of the documents established the discursive position taken by each actor. Next, the documents were coded using NVivo qualitative analysis software, based on the themes that emerged from the first reading. Finally, we considered how the texts reflected core principles and justifications associated with copyright.

\section{Legitimation strategies: industry to user}

Early communication from rights holders to users that sought to tackle piracy adopted hardline approaches in campaigns that criminalized users without differentiating between organized counterfeit rings and those who shared content on a small scale in their daily routines. From the 1980s onwards, industry depictions of the media user used the pejorative 'pirate' label to reinforce the notion that unscrupulous use of cultural products constituted theft and posed a significant threat to the cultural industries. In the UK, the BPI took up the link between crime and illicit domestic copying in its 'Home-taping is Killing Music' campaign. By adding a cassette to the Jolly Roger flag, the campaign cast the fan practices of taping the top 40 and making mixed tapes as piratical. The discourse of criminalization continued into the 2000s, with the Motion Picture Association of America's (MPAA 2004) 'Piracy: It's a Crime' (2004) campaign, which equated illegal downloading online with the theft of physical objects, such as handbags, cars and DVDs (see also Rutter 2010). Such campaigns were extensively parodied: the BPI campaign's Jolly Roger emblem was co-opted by the Pirate Bay, while the MPAA (2004) campaign was lampooned in the British television sitcom The IT Crowd (2006). The discourse of criminalization persists today to some extent, but is generally restricted to enforcement and lobbying activities by trade organizations like the Alliance Against IP Theft (AAIPT, recently re-branded as the Alliance for Intellectual Property) and the Federation Against Copyright Theft (FACT) (Edwards et al. forthcoming).

Rights holders have more recently changed tack in their communications to and about media users. Campaigns now tend to emphasize the pleasure and pride experienced by the consumption of cultural products and users are presented as partners with, rather than opponents of, industry. Within these campaigns, copyright is justified to users both instrumentally (in terms of its beneficial effects) and intrinsically 
(as a valued end in itself). Consumers should consume legally in order to ensure the production of the cultural goods they enjoy and of which - as national products - they might be proud. At the same time, they are also morally obliged to consume legally in order to give cultural workers the rewards to which they are entitled. The user-directed campaigns tend to engage with users on an emotional level, emphasizing the satisfaction derived from consumption and the suffering imposed on others as a result of copyright infringement.

Legal consumption is justified in terms of supporting the creation of products that bring consumers pleasure. For example, in the Industry Trust campaign, Moments Worth Paying for (Industry Trust 2011), a series of slow-motion films directed by Olly Blackman, entitled Shock, Laughter, Tears and Joy, capture the emotions on viewers' faces as they watch movies. The trailers were shown in cinemas and on the association's website, where the message behind the trailers is made explicit:

These are moments worth paying for. To be enjoyed as their makers intended: in official ways that help to protect the future of film and TV, thanks to that tiny, but powerful (C) aka copyright.

Moments Worth Paying For is the Industry Trust's new pro-copyright campaign that celebrates those who make great movies possible - the audience. (Industry Trust 2012a)

Payment is the appropriate route to enjoyment because that is what 'makers intended', it is 'official' and it will 'protect' the industry. Buying a cinema ticket becomes a symbolic act of loyalty, made possible by copyright since it is the reason we must buy a ticket to see a movie legally. This logic leads to the inevitable conclusion that a pro-copyright campaign equates to a celebration of the legally consuming audience, who ensure great movies are produced.

Another Industry Trust campaign in 2010, You Make the Movies, comprises a series of trailers directed by Steve Bendelack that parody famous film scenes. At the end of each, a voiceover reminds viewers, 'You make the movies. Every time you buy a cinema ticket, Blu-ray disc, DVD or download, your support helps us make the films you love: thank you' (Bendelack/Industry Trust 2010). Here, the roles of consumer and producer merge: consumers do not simply watch movies, they make them. Buying a ticket or DVD is redefined as 'support' rather than a 'purchase' (a market-based description, which could have been used), and defines the consumer as someone who is on the industry's side in the struggle against infringement. The partnership is symmetrical: the industry gratifies consumers by providing films they 'love'. However, 'partnership' is superficial in the end. Consumers may be partners, but their role is clearly defined: they must pay for their pleasure.

Rights holders sometimes also make more specific appeals to the national identities of users to encourage legal consumption. For example, the Connected to British Film and TV website, launched in 2009, 'celebrates Britain's World-Class film and TV industry' (Industry Trust 2012a). Additionally, the Industry Trust campaign stimulates the consumer to appreciate that they are central to the production of a globally recognized film and TV industry in the UK. It emphasizes the 'vital role' consumers play in making the British film and TV industry successful and calls upon feelings of national pride and, consequently, responsibility (Industry Trust 2012a). 
These discourses tend to justify copyright in terms of its instrumental benefits: the copyright regime is justified insofar as it supports the creation of things that consumers love and which inspire national pride. As already noted, however, the campaigns also draw upon a more intrinsic view of copyright. For example, the Industry Trust uses the voices, names and stories of behind-the-scenes workers such as runners and make-up artists, to demonstrate how cultural labourers are working hard to earn a living (Industry Trust 2012b). Such cultural-worker-witnessing emphasizes that illegal downloading is not a victimless crime, a message categorically reinforced with a statement of fact: 'you'll find that fake DVDs and illegal downloads cause serious damage which affects a wide range of people trying hard to earn a living within the film industry' (Industry Trust 2012c). Behind such campaigns is the moral claim that creative workers deserve to be rewarded for their efforts. They seek to give a moral face to what might otherwise appear as a faceless industry.

Adopting a similar approach when launched in 2010, the music industry's Music Matters campaign encourages digital music users to consume media only from websites that bear the 'Music Matters Trustmark':

Look out for the Music Matters Trustmark

As a music fan, the most important thing you can do is consume music in an ethical way.

With so many different ways to stream and download music, it can be confusing to work out which ones will support the musicians you love. That's why we've developed the Music Matters Trustmark.

Remember to look out for the Music Matters Trustmark whenever you are choosing new music.

Spread the word

Do your friends and family value music and know about the hard work that goes into making each song?

Help us build a strong movement supporting musicians everywhere, by inviting everyone you know to join the campaign. (Music Matters 2012)

The language used here is pedagogical and instructive: the Music Matters Trustmark clarifies how consumers can act 'ethically'. Fans should 'remember' to look out for the Trustmark and 'help' to build a strong movement by 'inviting' others to join the campaign. Complex matters of opinion (e.g. the most important aspect of being a fan is to consume music ethically) are transformed into fact. Interestingly, there are no consumers or purchases, only listeners and (confused) fans. Only the broader context of the campaign indicates that ethical support for musicians means paying for music. As in the Industry Trust's campaigns, the absence of marketing language allows the act of paying to be reinterpreted as a symbolic acknowledgement of music's enduring value, supporting 'musicians you love' and valuing the 'hard work' required to make music. The text also expresses a moral imperative, which ostracizes those who do not pay as lacking morality because they do not acknowledge or reward the work involved in music. Confusion 
is no excuse: Music Matters brings clarity and therefore eliminates the possibility of unintentional infringement. Ultimately, the fan is co-opted as a partner in the Music Matters 'movement' in order to work with artists and industry workers in a 'collective effort' to educate consumers.

The user-focused campaigns of rights holders are challenged by oppositional groups. While these groups may not always have the same ability to reach and address users directly, they circulate alternative messages in the public sphere that question and problematize the claims of rights holders. For example, groups such as ORG and Creative Commons question the reduction of the users of digital media to consumers whose contribution to creativity is limited to supporting industry products. They argue that digital technologies blur the distinction between producers and consumers, allowing users to become creators themselves and making it possible for new and more decentralized economic models to emerge: 'The Internet has turned consumers into creators and creators into small businesses that are not necessarily mediated by large intermediaries such as record companies and publishers' (ORG 2012b). In this context, digital copyright regulation is seen as being too 'restrictive' (Creative Commons 2006), as 'stifling' (ORG 2012c) rather than promoting new forms of creativity, and as benefiting rights holders rather than the public. As ORG (2012d) argues:

The digital age is transforming society: we believe it has the capacity to bring us greater democracy, transparency and new creative and social possibilities. But our freedoms are also under attack in the digital world: from governments and vested business interests.

Meanwhile, the communications of campaign groups like FAC complicate the moral arguments employed by rights holders about the harms that copyright infringement causes to creative workers. They point to the inequitable nature of industry structures and how the interests of artists are not synonymous with those of corporations. As such, they campaign for 'artists to have more control of their music and a much fairer share of the profits it generates in the digital age' (FAC/MMF 2011). As Billy Bragg, one of the artists involved in FAC, puts it, 'I believe my back catalogue should be my pension and not that of some geezer at a record company' (cited in Young 2009). Likewise, the artist Kate Nash explains that '[a]rtists don't currently have a seat at this negotiating table that we need. There are a lot of deals and decisions being made on our behalf that we have no say in' (cited in Young 2009).

To sum up, rights holders have shifted the emphasis away from the criminalization and vilification of users in more recent user-focused campaigns. Campaigns now focus on reminding consumers of the crucial role they play in the industrial structure. Industry and users are depicted as equal partners and as guardians of (British) creativity. This partnership is justified (instrumentally) in terms of the personal benefits reaped from legal consumption and (intrinsically) through the moral imperative to recognize and reward creative workers. As we have seen, these discourses are challenged by alternative messages circulated in the public sphere. Not surprisingly, however, there is little sign of these oppositional discourses within industry campaigns themselves. Websites are often interactive, linking to social media (Twitter, Facebook and YouTube), and users are encouraged to 'Tell us why music matters to you' and to show support for artists (Music Matters 2012). Yet, 
despite these invitations to proffer opinion, the generic structure of the marketing campaign confines users to a role of (legitimate) consumer. Voice and vote translate to the capacity to spend money: there is little room for discussion or dissent, with users only able to express their love and support for music, film and TV, rather than debate the legitimacy - or not - of the current copyright regime.

\section{Legitimation strategies: industry to government}

In their submissions to government reviews, rights holders defend the existing copyright regime robustly. The system is represented as flexible enough to adapt to economic and technological change and as either balanced (fair to both rights holders and to the public) or else, thanks to digitization and industry adaptation, tilted in favour of the consumer (BVA 2006, UK Music 2011). Where submissions do invite government action is in dealing with the problem of copyright infringement. Indeed, some argue that the copyright system itself, and the means of protecting it, should be more robust. In justifying the current copyright regime, the submissions draw primarily upon an instrumental view of copyright, arguing that copyright is necessary in order to establish an efficient market that generates benefits for both consumers and the national economy. The intrinsic view of copyright is less evident than in the user-facing material, but it is not entirely absent and at times rights holders draw upon it to justify their views.

In the industry submissions, the copyright regime is represented as being essential in order to support and facilitate cultural production. Indeed, creativity tends to be conflated with the copyright regime, such that the only incentive for creativity is financial. Consider, for example, the following quotation from Warner Bros. (2006, p. 2):

IP [Intellectual Property] rights are the cornerstone to facilitating, creating, distributing, and monetizing creative works. If one thinks of the media and entertainment industries as built upon creativity, then the industry looks at protection and growth of creativity as resting upon IP protection.

The protection and growth of creativity is here equated with a chain of marketization processes (facilitating, creating, distributing, and monetizing). The categorical claims presented as statements of fact leave little room for argument, and the instrumental importance of copyright in ensuring creativity is confirmed through its description as a 'cornerstone'. Other submissions use similar semantic techniques (BVA 2006, p. 5): copyright is the 'bedrock' (UK Music 2011, n.p.) or 'currency' (BPI 2006, p. 14) of the cultural industries.

Copyright is viewed as essential then in facilitating an efficient market in cultural production. Without copyright, there would be 'market failure', since the incentive to engage in cultural production would be removed. As Warner Bros. (2006, p. 2) put it:

IP laws are an attempt to remedy the market failure by granting investors in knowledge goods certain exclusive rights to exploit their creation in ways which allows the right owner to raise the retail price above marginal costs, for a specific period of time, and to generate a contribution towards the fixed production costs.

Submissions suggest that there are other ways that the market in cultural production is unique, which may mean that investors need additional protection. Compared 
with other industries, investment in cultural production is inherently unpredictable and 'risky'. As the BPI (2006, p. 6) argues, 'The record company (the investor and risk taker) currently faces the most challenging risk/reward ratios in the entrepreneurial world. And this is true whether one is a multinational or a minor player'. By referring both to large and small companies, the BPI omits the fact that risks are much greater for smaller companies than for larger ones, since the latter can balance risks more easily because of their size. Indeed, this is one reason why there is a tendency towards the concentration of ownership in the cultural industries (Hesmondhalgh 2007, p. 22).

Alongside general market-based discourses, the submissions also appeal more specifically to national economic interests. The 'creative industries' are represented as crucial in allowing the UK to find a niche and succeed in a global economy. Submissions are peppered with statistics to substantiate this claim. For example, the BPI (2011, p. 16) states that: 'The recorded music industry as a whole employs over 100,000 people and has a combined turnover of around $£ 4$ billion', while the BVA (2011, p. 1) states that the video entertainment sector of the UK's audiovisual industry is worth $£ 2.6$ billion. This is combined with claims that modifications to the copyright system that relax protections will threaten the UK's economic position. Given copyright's central role, industry submissions urge the government to move quickly to improve enforcement. The BPI warns: 'If swift action is not taken in the UK, Britain is also in danger of suffering a "creative crunch" (BPI 2011, p. 6). Here, national economic security and prosperity are the goods that are seen to follow, instrumentally, from the existing copyright regime.

Meanwhile, the submissions anticipate and seek to reject claims about the benefits of the public domain, where cultural goods are freely available to the public without restriction. In the following quotation, the BPI (2006, pp. 26-27) projects a culturally barren image of the future, rather than a 'golden age', resulting from the expiry of copyright and the release of products into the public domain:

Much of that [popular] music [of the 1950s and 1960s] is destined to fall into the public domain over the next 15 years. Far from this auguring in a golden age in which thousands of obscure recordings are suddenly rescued from the vaults and made available to a grateful public, the likelihood is that this will result mainly in a slew of poorly packaged 'hits' collections of variable quality, with none of the proceeds finding their way back to the original creators and investors.

As the BPI represents it, therefore, the public domain is not a site of future creativity, but a constraint on the production of quality cultural goods through the market.

Since 'none of the proceeds' are returned 'to the original creators and investors', the public domain is also constructed by the BPI (2006) as lacking morality. As this suggests, while the submissions tend to rely mostly on an instrumental view of copyright, rights holders also draw at times on a more intrinsic conception that justifies copyright as a valuable end in itself and a reward that creators rightfully deserve. For example, UK Music states: 'Enforcement of copyrights is also about equality and justice. Individual creators, performers, rights holders should have access to justice when their rights are infringed' (UK Music 2011, n.p.). Copyright is represented as legitimate, then, because it is aligned with moral concerns relating to justice, to which creative workers and corporate rights holders are both entitled because their moral claims over cultural products are apparently one and the same. 
As with the user campaigns, the discursive claims that rights holders make - whether based on instrumental or intrinsic justifications of copyright - are challenged and critiqued by groups in other submissions. Some groups, for example, question the claim that creativity is synonymous with the current copyright regime, by locating creativity outside as well as inside industry structures. Rights holders are seen as exaggerating the instrumental benefits of the existing copyright system and as ignoring how copyright may obstruct as well as promote creativity. For example, Creative Commons (2006, p. 2) contrasts strict copyright regulation with the public access and creativity made possible through digital media: 'The restrictive nature of maximized copyright protection is thrown into stark relief by the potential for access, use and reuse of content made possible by digital technologies'. Similarly, in its submission to the Hargreaves Review, ORG (2011, n.p.) argues that copyright policy is failing to strike the right balance and is having a detrimental rather than a positive effect:

\begin{abstract}
We feel that policy making around copyright has, up until now, [...] rested on a rather unbalanced position regarding what effective role IP can play in innovation and growth. This is evident from the Digital Economy Act, in the moves to extend copyright terms covering sound recordings at a European level, through to the Anti-Counterfeiting Trade Agreement.
\end{abstract}

These are manifestations of an approach to copyright that has restricted the adjustment of the creative economy to the digital age, with consequent negative effects on creativity, on the creative economy, on the interests of consumers and on social and economic innovation. It prioritises restriction and punishment, is not supported by robust evidence and works against the interests of citizens and consumers.

The claim by rights holders that the current copyright regime best serves the UK's national economic interests is also disputed by some submissions. For example, despite stating that it supports UK Music's submission to the Hargreaves review, AIM argues on behalf of the independent music sector that 'Independent music companies are now the only UK-owned, UK-run music industry sector: all the major multinationals are now foreign-owned' and hence do not function 'as part of indigenous UK business' (AIM 2011, p. 1). AIM's observations, therefore, seek to undermine the music industry's claim about the need to protect British interests (creativity, revenue and employment).

Finally, other submissions challenge the presentation of the cultural industries as having singular interests. FAC/MMF's submission illustrates this well, drawing attention to facets of the copyright system that weigh heavily in favour of companies rather than artists. In contrast to PACT's observation that, 'copyright is, and should remain, the way in which creators are potentially able to receive recognition and secure a return for their work' (PACT 2011, p. 27), FAC/MMF argues for the addition of measures that will make this realizable and protect creators who might otherwise have to sacrifice their copyright to larger music conglomerates. FAC/MMF argues that the rights of creators should be recognized and made unwaivable and that copyright only be transferable for a limited period, meaning that it returns to the creator 'at least once in their lifetime' (FAC/MMF 2011, p. 2). It also believes that 'all transfers of copyright should only be by license and that assignment should be prohibited. That way ownership of the copyright always 
remains with the creator' (FAC/MMF 2011, p. 2). By pointing to the power imbalances that exist within the copyright system and calling for fairness on behalf of creative workers, FAC/MMF render questionable the moral terrain underlying the cultural industries' intrinsic justifications of copyright and pleas for 'justice and equality'.

Overall, our analysis reveals how rights holders seek to legitimate the copyright regime to government by emphasizing its instrumental value (in supporting cultural production and the national economy) and to a lesser extent its intrinsic value (as moral recognition and reward for cultural production). However, these same discourses are open to challenge by other groups who - while they do not necessarily disagree with the principles espoused - question their interpretation and the evidence used to support them. Given the structure of consultations, as with the user campaigns, rights holders need not respond directly to the counterclaims that opponents make. The consultation is limited to single, discrete inputs without there being opportunities for actors to continue to contest, respond to, or develop each other's ideas. We might say that rights holders' discursive claims are not, in Mayhew's (1997, p. 13) terms, fully 'redeemed', where 'to redeem a rhetorical claim' is 'to respond to demands for clarification, specification, and evidence'. The redemption of discursive claims would require a more thoroughly deliberative process of policy-making where different positions could be clarified and fully debated and worked through (Habermas 1997, Young 2002).

\section{Conclusion}

Discourse has been an important weapon in 'the copyright wars' (Lessig 2008). As our analysis has shown, rights holders in the cultural industries have employed discourse strategically in order to try and legitimate their position and promote their interests with both users and government. At the same time, following Boltanski and Chiapello (2005) and Boltanski and Thévenot (2006), we have argued that in legitimating economic arrangements, actors must appeal to general justificatory principles that make a broader claim to legitimacy. The circulation of these claims provides the raw material for critique, as other groups can contest the interpretation of these principles and the evidence used to support them. For example, arguments that associate legal consumption with moral integrity are countered by discourses that reveal the inequitable nature of industry structures and how the interests of corporations and creative workers diverge. Likewise, instrumental justifications of the current copyright regime are questioned by those who emphasize how long and restrictive copyright protections obstruct creativity, while the claim that copyright furthers Britain's national interests is challenged by those who point to foreign ownership.

What implications do these findings have for the development of sustainable and legitimate digital copyright policy? There are signs that rights holders may be winning their war against 'piracy', as revenues from digital services - be it through online subscriptions, advertising or per-copy payments - increase. According to the BPI (2012), for example, revenues for recorded music in the UK rose by $2.7 \%$ in the first quarter of 2012, with digital revenue accounting for the majority $(55.5 \%)$ of this revenue for the first time. Despite ongoing 'fighting' over piracy, Zittrain (2012, n.p.) suggests that the 'lines for détente on straight-out copying are drawn: there's been uptake of all-you-can-eat subscriptions through services such as 
Spotify or Netflix, and pay-per-item stores such as the iTunes store'. Perhaps, then, the industry's user-directed campaigns and other measures are seeing some success. But then, even if Zittrain's forecast is right, it does not necessarily equate to a legitimate fix to current copyright policy and it leaves important questions about copyright unanswered.

In understanding copyright debates as processes of justification and critique, we suggest there is the hope of achieving a more legitimate resolution to the copyright wars - that is, a resolution which is in the public interest - or at least the possibility of beginning a more constructive dialogue. Such a dialogue would require the involvement of all affected parties and a structured form of deliberation where different positions could be fully aired, clarified and worked through (Habermas 1997, Young 2002). It would need to meaningfully involve members of the public themselves as a source of legitimate perspectives, not just as copyright infringers who need to be better educated or regulated: as argued elsewhere, users are more than capable of offering rational justifications in relation to copyright, even in the absence of clear and detailed knowledge about it (Edwards et al. 2013). However, as we have described, the 'generic structures' through which copyright policy is currently debated are limited because they do not require participants to engage directly with each other. In government consultations and even more so in industry campaigns, rights holders (as well as other groups for that matter) need not respond fully to counter arguments or account publicly for the apparent limitations and inconsistencies in the justificatory discourses they employ. So while justificatory claims are evident, these claims are not fully 'redeemed' (Mayhew 1997, p. 13).

In addition, policy consultations do not always translate neatly into political outcomes and may be short circuited by other processes such as the direct lobbying of politicians (Freedman 2008, pp. 80-105). Hargreaves (2011, p. 18) refers to the problem of 'lobbynomics' in copyright policy, explaining that 'there is no doubt that the persuasive powers of celebrities and important UK creative companies have distorted policy outcomes' (Hargreaves 2011, p. 93). The recent extension of copyright in sound recordings and performers' rights in sound recordings is one example of where policy outcomes have diverged from the recommendations of policy reviews. Gowers (2006) had concluded in his review there was no instrumentaleconomic rationale and public benefit for extending the term beyond 50 years. However, in 2011, the copyright term was extended by government to 70 years following lobbying by rights holders. At the time of writing, it is still not clear whether the modest proposals for a private copying exception to benefit users, suggested by Hargreaves, will be implemented or not.

There may still be public opposition to the discourses of corporate rights holders in the cultural industries and to the forms of copyright policy and regulation they promote, as reflected by the recent protests against the Stop Online Piracy and Protect Intellectual Property Acts in the United States and similar actions elsewhere. However, rights holders' strategic use of discourse reinforces the structural advantages they already tend to enjoy in the copyright debate. As a result, the copyright debate remains a far cry from a more deliberative process of copyright policy-making where a more legitimate détente to the copyright wars may be achieved. 


\section{Acknowledgements}

We would like to express our thanks to David Berry for discussions of the ideas developed in this article and the anonymous reviewers for their comments. An earlier version of this paper was presented at the 2013 International Communication Association Conference in London, UK.

\section{Funding}

This work was supported by the Economic and Social Research Council [grant number RES-062-23-3027].

\section{Note}

1. Copyright is currently the life of the creator plus 70 years for original creative works in the UK. Copyright in broadcasts and sound recordings lasts for 50 years, although the European Union agreed a directive in 2011 to increase the period of sound recordings to 70 years (IPO 2013).

\section{References}

Association of Independent Music (AIM), 2011. Submission to the Hargreaves review of intellectual property and growth. Available from: http://www.ipo.gov.uk/ipreviewc4e-sub-aim.pdf [Accessed 25 July 2013].

Baker, C.E., 2002. Media, markets, and democracy. Cambridge: Cambridge University Press.

Bendelack/Industry Trust for IP Awareness, 2010. You make the movies. Available from: http://www.connectedtobritishfilmandtv.co.uk/\#/you-make-the-movies [Accessed 31 October 2012].

Bettig, R., 1996. Copyrighting culture: the political economy of intellectual property. Boulder, CO: Westview.

Boltanski, L. and Chiapello, È., 2005. The new spirit of capitalism. Trans. G. Elliott. London: Verso.

Boltanski, L. and Thévenot, L., 2006. On justification: economies of worth. New ed. Trans. C. Porter. Princeton, NJ: Princeton University Press.

Bowrey, K., 2005. Law and internet cultures. Melbourne: Cambridge University Press.

Boyle, J., 2010. The public domain: enclosing the commons of the mind. New Haven, CT: Yale University Press.

British Recorded Music Industry (BPI), 2006. The Gowers review of intellectual property: a response from the British Phonographic Industry. Available from: http:// www.hm-treasury.gov.uk/d/british_phonographic_industry_306_160 kb.pdf [Accessed 31 October 2012].

British Recorded Music Industry (BPI), 2011. Independent review of intellectual property and growth: response of the BPI. Available from: http://www.ipo.gov.uk/ipreview-c4e-sub-bpi. pdf [Accessed 29 October 2012].

British Video Association (BVA), 2006. Gowers review of intellectual property: BVA. Available from: http://webarchive.nationalarchives.gov.uk/+/http://www.hm-treasury.gov.uk/ d/british_video_association_260_372 kb.pdf [Accessed 31 October 2012].

British Video Association (BVA), 2011. Response to the independent review of IP \& growth. Available from: http://www.ipo.gov.uk/ipreview-c4e-sub-bva.pdf [Accessed 29 October 2012].

BPI, 2012. Digital revenues overtake physical in UK recording market. Available from: http://www.bpi.co.uk/media-centre/digital-revenues-overtake-physical-in-uk-recorded-musicmarket.aspx [Accessed 18 August 2013].

Chiapello, E. and Fairclough, N., 2002. Understanding the new management ideology: a transdisciplinary contribution from critical discourse analysis and new sociology of capitalism. Discourse \& society, 13 (2), 185-208. 
Creative Commons, 2011. The power of open. Available from: http://thepowerofopen.org/ [Accessed 25 July 2013].

Creative Commons, 2006. Submission to the Gowers review of intellectual property. Available from: http://webarchive.nationalarchives.gov.uk/+/http://www.hm-treasury.gov.uk/ media/3/2/creative_commons_418_p1_936 kb.pdf.

David, M., 2010. Peer to peer and the music industry: the criminalization of sharing. London: Sage.

Deazley, R., 2006. Rethinking copyright. Cheltenham: Edward Elgar.

Department for Business, Innovation and Skills/Intellectual Property Office, 2009. (C) The way ahead: a strategy for copyright in the digital age. London: Department for Business, Innovation and Skills.

Department of Business, Enterprise and Regulatory Reform (BERR), 2008. Consultation on legislative options to address illicit peer-to-peer $(P 2 P)$ file-sharing. London: BERR.

Department of Business, Innovation and Skills/Department of Culture Media and Sport (BIS/DCMS), 2009. Digital Britain final report. London: The Stationery Office.

Department of Culture, Media and Sport Select Committee (DCMS), 2007. New media and the creative industries. London: The Stationery Office, Fifth Report.

Drahos, P., 1996. A philosophy of intellectual property. Dartmouth: Dartmouth Publishing.

Drahos, P. and Braithwaite, J., 2002. Information feudalism: who owns the knowledge economy. London: Earthscan.

Duff, A., 2008. The normative crisis of the information society. Cyberpsychology: journal of psychosocial research on cyberspace, 2 (1). Available from: http://cyberpsychology.eu/ view.php?cisloclanku $=2008051201 \&$ article $=[$ Accessed 4 November 2012].

Edwards, L., Klein, B., Lee, D., Moss, G., and Philip, F., 2013. Isn't it just a way to protect Walt Disney's rights?: Media user perspectives on copyright, New Media \& Society [online]. doi:10.1177/1461444813511402.

Edwards, L., Klein, B., Lee, D., Moss, G. and Philip, F., forthcoming. Communicating copyright: Discourse and disagreement in the digital age. In: Matthew David and Debora Halbert, eds. SAGE handbook of intellectual property. London: SAGE.

Fairclough, N., 2003. Analysing discourse: textual analysis for social research. London: Routledge.

Fairclough, N., 2004. Critical discourse analysis and change in management discourse and ideology: a transdisciplinary approach to strategic critique. University of Lancaster. Available from: http://www.ling.lancs.ac.uk/staff/norman/paper5.doc [Accessed 31 July 2012].

Featured Artists Coalition/Music Managers Forum (FAC/MMF), 2011. The FAC and MMF submission to the Hargreaves review. Available from: http://www.ipo.gov.uk/ipreview-c4esub-featured.pdf [Accessed 31 October 2012].

Freedman, D., 2008. The politics of media policy. Cambridge: Polity Press.

Gowers, A., 2006. Gowers review of intellectual property. London: HM Treasury.

Habermas, J., 1989. The theory of communicative action. Boston, MA: Beacon Press.

Habermas, J., 1991. Communication and the evolution of society. Oxford: Polity.

Habermas, J., 1997. Between facts and norms: contributions to a discourse theory of law and democracy. London: Polity Press.

Hargreaves, I., 2011. Digital opportunity: a review of intellectual property and growth. London: HM Treasury.

Hesmondhalgh, D., 2006. Digital sampling and cultural inequality. Social \& legal studies, 15 (1), 53-75.

Hesmondhalgh, D., 2007. The cultural industries. 2nd ed. London: Sage.

Industry Trust for IP Awareness, 2009. Connected to British film \& TV campaign. Available from: http://www.connectedtobritishfilmandtv.co.uk/ [Accessed 29 October 2012].

Industry Trust for IP Awareness, 2011. Moments worth paying for. Available from: http://www.copyrightaware.co.uk/about-the-industry-trust/mwpf/moments-worth-paying-forvideos.asp [Accessed 20 October 2012].

Industry Trust for IP Awareness, 2012a. Our campaigns. Available from: http://www. copyrightaware.co.uk/ [Accessed 31 October 2012].

Industry Trust for IP Awareness, 2012b. Behind the scenes. Available from: http://www.copy rightaware.co.uk/ [Accessed 31 October 2012]. 
Industry Trust for IP Awareness, 2012c. Copyright theft. Available from: http://www. copyrightaware.co.uk/ [Accessed 31 October 2012].

Intellectual Property Office (IPO), 2013. How long copyright lasts. Available from: http:// www.ipo.gov.uk/types/copy/c-duration.htm [Accessed 15 August 2013].

Jessop, B., 2002. The future of the capitalist state. Cambridge: Polity Press.

Kawashima, N., 2010. The rise of 'user creativity' - web 2.0 and a new challenge for copyright law and cultural policy. International journal of cultural policy, 16 (3), 337-353.

Kretschmer, M. and Kawohl, F., 2004. The history and philosophy of copyright. In: S. Frith and L. Marshall, eds. Music and copyright. Edinburgh: Edinburgh University Press, 21-53.

Lessig, L., 2004. Free culture: how big media uses technology and the law to lock down culture and control creativity. New York: Penguin.

Lessig, L., 2008. Remix. London: Bloomsbury.

Lindgren, S., 2013. Pirate panics: comparing news and blog discourse on illegal file sharing in Sweden. Information, communication \& society. Available from: http://www.tandfonline.com/ doi/full/10.1080/1369118X.2012.757632\#tabModule [Accessed 14 August 2013].

Macmillan, F., 1998. Copyright, culture and private power. Prometheus, 16 (3), 305-316.

May, C., 2003. Digital rights management and the breakdown of social norms. First monday, 8 (11). Available from: http://firstmonday.org/htbin/cgiwrap/bin/ojs/index.php/ fm/article/viewArticle/1097/1017 [Accessed 1 November 2012].

May, C., 2004. Commodifying the 'information age': intellectual property rights, the state and the internet. SCRIPT-ed, 1 (3), 408-419.

Mayhew, L.H., 1997. The new public. Cambridge: Cambridge University Press.

Motion Picture Association of America (MPAA), 2004. Piracy. It's a crime. Available from: http://www.youtube.com/watch?v=HmZm8vNHBSU.

Music Matters, 2012. The campaign. Available from: http://www.whymusicmatters.com [Accessed 10 December 2012].

Open Rights Group (ORG), 2006. Open rights group submission to the Gowers review. Available from: http://wiki.openrightsgroup.org/wiki/Gowers_Review_Submission [Accessed 25 October 2012].

Open Rights Group (ORG), 2011. Hargreaves review of IP and growth: Open Rights Group (ORG) submission. Available from: http://www.ipo.gov.uk/ipreview-c4e-sub-org.pdf [Accessed 28 October 2012].

Open Rights Group (ORG), 2012a. Website. Available from: http://www.openrightsgroup.org/ [Accessed 5 May 2012].

Open Rights Group (ORG), 2012b. Copyright reform. Available from: http://www. openrightsgroup.org/issues/copyright-reform [Accessed 5 May 2012].

Open Rights Group (ORG), 2012c. Why copyright law needs a sense of humour. Available from: http://www.openrightsgroup.org/ [Accessed 5 May 2012].

Open Rights Group (ORG), 2012d. Our work. Available from: https://www.openrightsgroup.org/ ourwork/ [Accessed 5 May 2012].

Pang, L., 2008. China who makes and fakes: a semiotics of the counterfeit. Theory, culture \& society, 25 (6), 117-140.

Postigo, H., 2008. Capturing fair use for the youtube generation: the digital rights movement, the electronic frontier foundation and the user-centered framing of fair use. Information, communication \& society, 11 (7), 1008-1027.

Postigo, H., 2011. Cultural production and the digital rights movement. Information, communication \& society, 15 (8), 1165-1185.

Producers Alliance for Cinema and Television (PACT), 2011. Response to independent review of intellectual property and growth: PACT. Available from: http://www.ipo. gov.uk/ipreview-c4e-sub-pact.pdf [Accessed 31 October 2012].

Rutter, J., 2010. Consumers, crime and the downloading of music. Prometheus, 28 (4), 411-418.

Rutter, J. and Bryce, J., 2008. The consumption of counterfeit goods: 'Here Be Pirates?'. Sociology, 42 (6), 1146-1164.

Smiers, J., 2005. Arts under pressure: promoting cultural diversity in the age of globalization. London: Zed Books.

Svensson, M. and Larsson, S., 2012. Intellectual property law compliance in Europe: illegal file sharing and the role of social norms. New media \& society, 14 (7), 1147-1163. 
Towse, R., 1999. Copyright, risk and the artist: an economic approach to policy for artists. International journal of cultural policy, 6 (1), 91-107.

UK Music, 2011. UK Music response to the call for evidence of the independent review of intellectual property and growth. Available from: http://www.ipo.gov.uk/ipreview-c4e-sub-ukmu sic.pdf [Accessed 31 October 2012].

Wang, S. and Zhu, J., 2003. Mapping film piracy in China. Theory, culture \& society, 20 (4), 97-125.

Warner Bros. Entertainment UK, 2006. Submission to the Gowers review of UK IP laws. Available from: http://www.hm-treasury.gov.uk/d/warner brothers entertainment uk $09735 \mathrm{~kb}$. pdf [Accessed 31 October 2012].

Yar, M., 2008. The rhetorics and myths of anti-piracy campaigns: criminalization, moral pedagogy and capitalist property relations in the classroom. New media \& society, 10 (4), 605-623.

Young, I.M., 2002. Inclusion and democracy. Oxford: Oxford University Press.

Young, I., 2009. Why music artists need a voice [BBC Online]. Available from: http:// news.bbc.co.uk/1/hi/entertainment/7939035.stm [Accessed 1 June 2013].

Zittrain, J., 2012. Don't let software patents stop us standing on the shoulders of giants. The Guardian, 18 April. Available from: http://www.guardian.co.uk/commentisfree/2012/apr/ 18/software-patents-shoulders-of-giants [Accessed 1 December 2012]. 